\title{
Repair of the myometrial scar defect at repeat caesarean section: a modified surgical technique
}

\author{
Shahul Hameed Mohamed Siraj ${ }^{1}$, Karuna Mary Lional ${ }^{2^{*}}$ (D) Kok Hian Tan ${ }^{2,3}$ and Ann Wright ${ }^{2}$
}

\begin{abstract}
Background: To investigate whether the existing surgical technique for uterine closure at repeat lower segment Caesarean section (LSCS) can be modified to achieve adequate residual myometrial thickness (RMT) to ensure scar integrity and reduce complications in future pregnancy.

Methods: Women with a significant scar defect at repeat LSCS had the anterior uterine wall closed by a single experienced obstetrician with a technique focused on recognition, mobilisation and apposition of the retracted myometrial edges at the boundary of the defect. This was aimed at anatomical restoration of the lower segment. The RMT at the scar area was assessed by postnatal pelvic ultrasound scan at three months.

Results: Thirty women with a history of at least one previous CS, incidentally found to have a large defect at operation underwent the technique with prior consent. A postnatal scan showed a mean residual myometrial thickness of $8.4 \mathrm{~mm}(\mathrm{SD} \pm 1.3 \mathrm{~mm}$; range $5.6-11.0 \mathrm{~mm}$ ). The average operating time was 91 mins and the average blood loss $728 \mathrm{ml}$. Two women who underwent the repair have gone on to have a further uneventful CS.

Conclusion: This modified technique resulted in scan evidence of an RMT indicative of uterine wall stability postnatally and offers the potential for reducing the risk of rupture and placenta accreta spectrum (PAS) in future pregnancy.
\end{abstract}

Keywords: Residual myometrial thickness, Caesarean scar dehiscence, Myometrial repair

\section{Background}

The myometrial niche and its subsequent development into a scar defect during pregnancy after caesarean section (CS) has been associated with various complications. The risk of uterine rupture increases with the size of defect, being higher with any scar thickness of $\leq 5 \mathrm{~mm}$ [1]. Abnormal placental implantation has also been linked to a large area of myometrial deficiency [2]. While niche repair has been performed for years for a variety of gynaecological indications and may be incorporated

\footnotetext{
* Correspondence: happykaruna@gmail.com; lional.karunamary@kkh.com.sg ${ }^{2}$ Department of Maternal Fetal Medicine, Division of Obstetrics and Gynaecology, KK Women's and Children's Hospital, 100 Bukit Timah Road, Singapore 229899, Singapore

Full list of author information is available at the end of the article
}

into the surgical management of scar pregnancy [3], apart from some highly specialised uterine conserving techniques used for placenta accreta spectrum (PAS) disorders, repair of the dehiscence at uncomplicated repeat CS has not been reported $[4,5]$.

The niche is an area of deficiency at the lower uterus which corresponds to the site of a previous operative delivery. It develops into an isthmocele as pregnancy progresses and may be classified as large or small depending on the wall thickness of the myometrial defect expressed as an absolute measurement or percentage. Niche incidence following prior CS has been reported as high as $84 \%$ using gel instillation sono-hysterography $[4,5]$. No niche has been reported without previous CS although

(C) The Author(s). 2021 Open Access This article is licensed under a Creative Commons Attribution 4.0 International License, which permits use, sharing, adaptation, distribution and reproduction in any medium or format, as long as you give appropriate credit to the original author(s) and the source, provide a link to the Creative Commons licence, and indicate if changes were made. The images or other third party material in this article are included in the article's Creative Commons licence, unless indicated otherwise in a credit line to the material. If material is not included in the article's Creative Commons licence and your intended use is not permitted by statutory regulation or exceeds the permitted use, you will need to obtain permission directly from the copyright holder. To view a copy of this licence, visit http://creativecommons.org/licenses/by/4.0/ The Creative Commons Public Domain Dedication waiver (http://creativecommons.org/publicdomain/zero/1.0/) applies to the data made available in this article, unless otherwise stated in a credit line to the data. 
localized myometrial deficiency is a recognized complication of previous gynaecological surgery. The risk of niche enlargement increases with number of previous CS and possibly uterine retroflexion. The aetiology of the niche is not fully understood and uterine incision site, often related to labour characteristics, surgical closure technique (single or double layer, locking sutures, with or without inclusion of the decidua, amongst others) and patient factors have all been suggested as possible contributors [6]. Complications of previous Caesarean section on subsequent pregnancies have been comprehensively documented and include uterine rupture with potentially catastrophic consequences for both fetus and mother which may be as high as $5 \%$ with a large defect [7]. Antenatal ultrasound assessment of myometrial thickness appears to have limited use as a prognosticator for obstetric outcomes but is a marker for uterine wall stability after repair at caesarean section $[8,9]$.

Many studies have looked at factors favouring vaginal birth after caesarean section (VBAC) but when considering the anatomical changes at the previous scar, success of VBAC would be expected, at least in part, to depend not only on the size of the myometrial defect but more importantly, the strength of the overlying pelvic fascia and any attached muscle $[8,10]$. Therefore, it is important during an elective or emergency repeat caesarean section to identify the retracted myometrial muscle and repair the defect to ensure integrity of the remaining scar.

\section{Altered anatomy of the lower uterus after caesarean section}

During formation of the lower uterine segment (LUS) after previous CS, the myometrium at the niche may separate and retract resulting in a scar defect, the depth of which is related to the amount of muscle affected [6]. The inferior retracted muscle edges which become epithelialized can be difficult to recognize and might be missed during closure at subsequent operative delivery, usually performed in two layers. This leads to further deepening and widening of the defect with each CS until only fascia exists between the pregnancy and bladder forming the myometrial scar defect or isthmocele which is often referred to as "the thin lower segment" and repaired without including the underlying muscle layers. The myometrial defect can be identified on pelvic ultrasound as a niche especially in early pregnancy but MRI is useful in later pregnancy as it can help to identify the retracted muscle edges [2].

We have observed that there is nearly always also thinning and tearing of the muscle layers in the posterior and lateral uterine walls which, we postulate, is due to the distribution of forces at the interface between the lower and upper uterine segments with advancing pregnancy (Fig. 1). We describe a technique which focuses on repair of the anterior uterine wall with recognition and correction of the myometrial defect resulting from a previous CS by mobilisation and apposition of the retracted muscle edges at the boundary of the defect allowing anatomical restoration and addresses any accompanying posterior wall damage and angle disruption.

\section{Methods}

We wanted to evaluate the efficacy of a modified technique for the repair of the myometrial defect at repeat caesarean section. The study was conducted, as a pilot, in a tertiary obstetric referral hospital in Singapore which has around 12,000 deliveries per year and a caesarean section rate of $30-32 \%$, between June and September 2019. All women having a repeat caesarean section done by a single senior obstetrician were counselled and written consent taken that if found to have a large scar dehiscence/ myometrial defect at surgery it would be formally repaired. Thirty women were identified at caesarean delivery to have a large dehiscence and underwent the repair with a postnatal scan organised at three months to measure RMT.

\section{Modified technique}

The abdomen was opened through the previous scar. The visceral peritoneum at the utero vesical junction, was divided to reveal the scar defect below and the bladder was dissected free from the lower uterus. The uterus was opened transversely through the lower third of the scar defect by a horizontal incision which was gently extended laterally using the index fingers or scissors and the baby was delivered in the usual way. The uterus was then repaired in the following steps:

\section{Step 1: Recognition of the retracted myometrium around the boundary of the myometrial defect}

\section{a. Lower (inferior) ring of muscle (Refer Fig. 1)}

The retracted anterior muscle edge at the inferior boundary of the defect was first sought. The bulk of this retracted lower myometrial muscle can be identified by running a finger up from the internal os superiorly to where the tissue first thins. This muscle band is grasped with Green Armytage clamps along its length. In cases of more than one previous CS where there may be more than one defect with several bands of muscle within the fascia, the lowermost band of muscle is followed laterally towards the angles and onto where it meets the attenuated muscle of the posterior uterine wall in the form of a ring. This allows all the retracted myometrium to be included in the repair. 


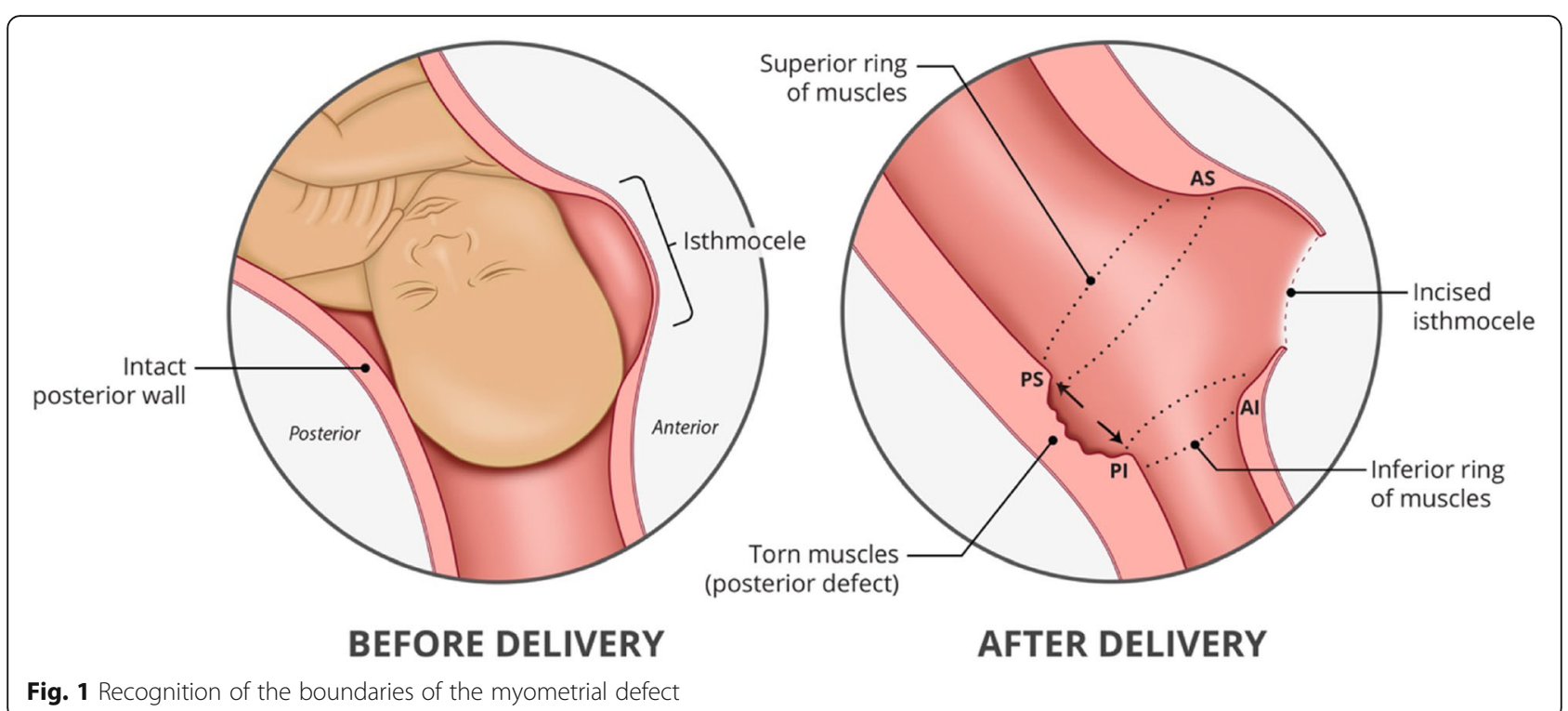

Fig. 1 Recognition of the boundaries of the myometrial defect

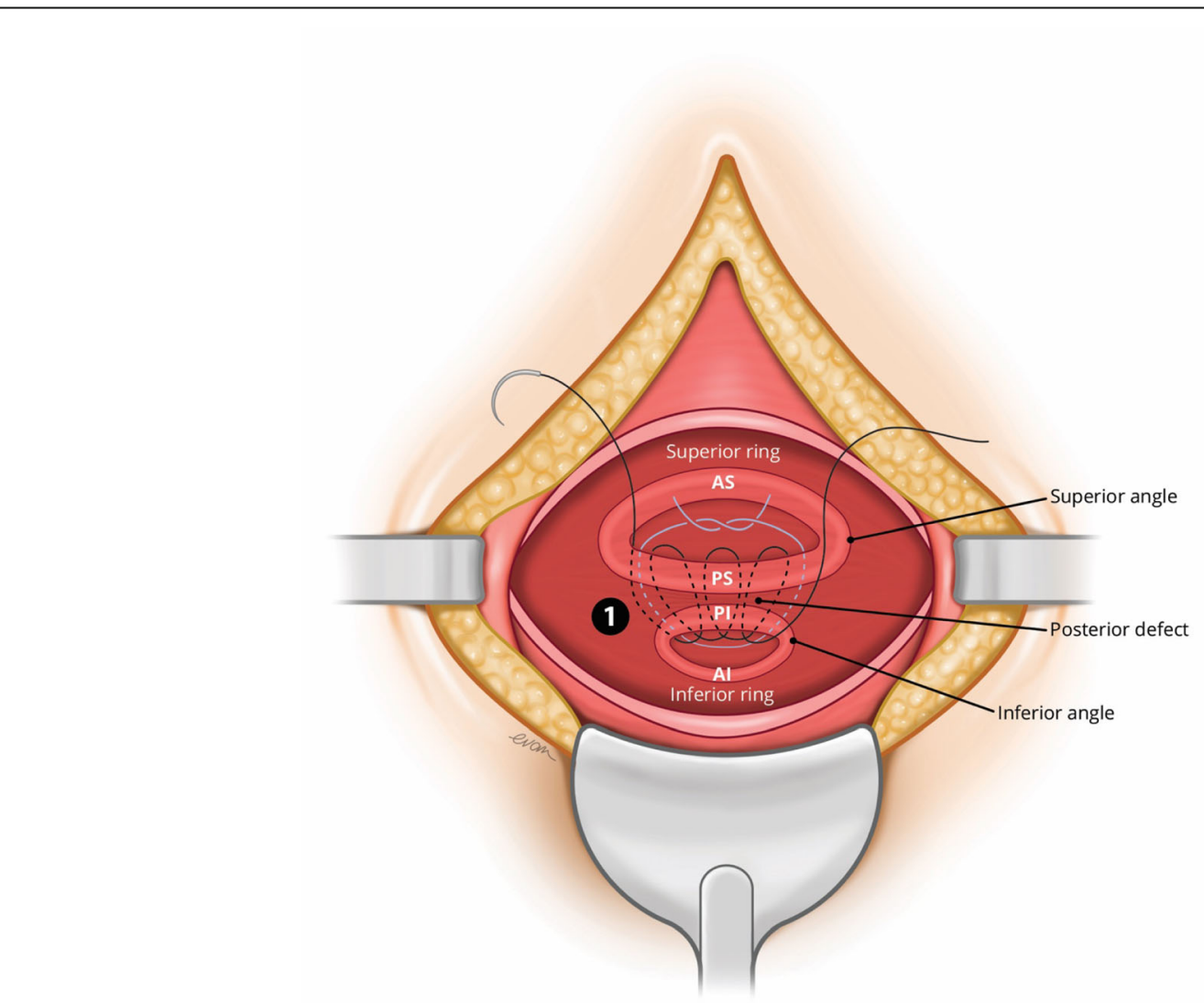

Fig. 2 Repair of the posterior wall defect 
b. Upper (superior) ring of muscle

The muscle at the upper anterior edge of the defect was identified and held with Green Armytage clamps and followed round posteriorly.

c. Identification of the posterior defect

Any additional posterior myometrial defect is then identified between the two muscle rings in the posterior uterine wall.

\section{Step 2: Re-attachment of the myometrial defect (superior and inferior retracted muscle ring) and closure of the anterior uterus}

After freshening, both the superior and inferior rings of muscle they were re-attached in the following order using a number polyglactin 910 1-0 suture on a round bodied needle: -

\section{a. Repair of the posterior wall defect (Refer Fig. 2)}

The torn posterior muscle edges were held between the two rings with clamps and placing a large horizontal mattress suture loosely to hold the muscle edges together before closing the gap between the edges with a continuous suture.

b. Reconstitution of the lateral angles (right and left) of the myometrial defect

Both torn lateral angles were reconstructed by identification and re-attachment to their ipsilateral origin. This reduced the tension before bringing them together bilaterally using a figure of eight suture.

c. Closure of the antero-inferior and antero-superior boundary of the myometrial defect continuous suture (Refer Fig. 3)

This step could be likened to bringing together two ends of a tube (with a thin posterior wall which has already been repaired). The initial layer needs to pick up the muscle at the base of the myometrial defect by inserting the needle perpendicular to the bulk of the muscle before bringing it through to the cavity and subsequently through the superior muscle from inside out. (Refer Fig. 4) Closing this layer by suturing from both angles and tying in the middle reduces the inadvertent risk of closing off the lower cavity.

\section{d. Completing the closure of the anterior uterine wall}

The remaining muscles were then closed in two or three layers depending on the bulk of muscles suturing from the angles by approximation of the upper and lower myometrial edges with the aim of building up and equalizing the depth of the superior and inferior aspects of the anterior uterine wall musculature and incorporating the fascia. Refer to Fig. 5 which illustrates the final appearance of the anterior and posterior wall defects after repair.

Following the closure, haemostasis was checked, the peritoneal cavity cleaned and the abdominal wall closed in layers in the usual way with polyglactin $9101-0 \mathrm{su}-$ tures to the rectal fascia, subcutaneous tissue and a subcuticular suture such as monocryl. Use of a drain and
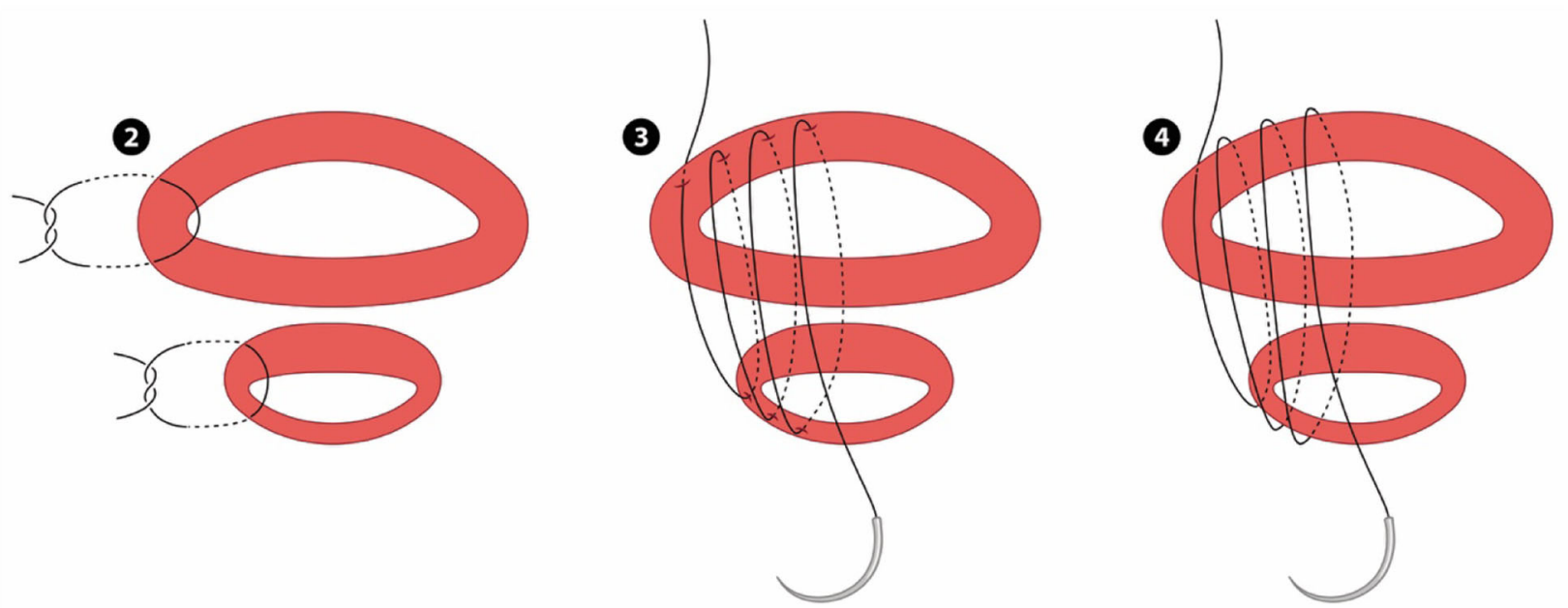

Fig. 3 Repair of the angles and anterior defect 


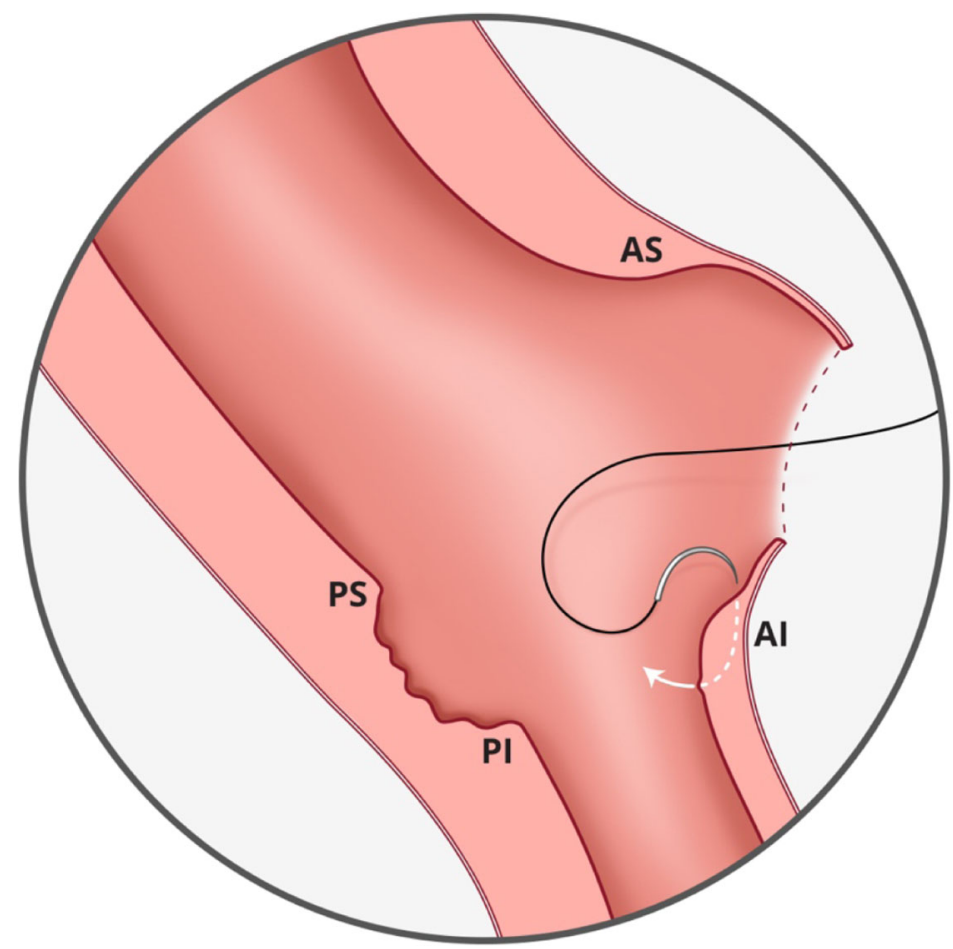

AS- Anterior superior

Al - Anterior inferior

PS- Posterior superior

$\mathrm{PI}$ - Posterior inferior

Fig. 4 Needle placement for myometrial repair. AS- Anterior superior. Al - Anterior inferior. PS- Posterior superior. PI - Posterior inferior

antibiotics were optional depending on the clinical situation. Post-operative care was the same as for all repeat Caesarean section.

This differs from the standard technique in which the uterus is usually opened transversely and, following delivery, closed in two layers to secure haemostasis with no particular attention to identification of the previously separated muscles as it requires the steps of formal identification and mobilization of the retracted lower segment myometrium. Mobilisation facilitates the recognition of the extent of the retraction in the anterior lower segment and allows recognition of the posterior wall shearing and defect both of which ensure optimal anterior and posterior approximation and closure of the lower segment myometrium.

\section{Results}

A total of 30 women, with a mean age of 31.8 years (SD \pm 4.8 years) and mean BMI of $27.2 \mathrm{~kg} / \mathrm{m}^{2}$ (SD \pm 4.8 $\mathrm{kg} / \mathrm{m}^{2}$ ) consented to undergo the technique if warranted. Of the 30 women, 23 had one previous CS; 6 had two; and one had three previous CS. Most of them (25(83.3\%)) had the CS at term for singleton pregnancies. Five were preterm (including twins at 36 weeks and an IUD at 28 weeks). The average operating time was $91 \mathrm{mins}$ (SD $\pm 20 \mathrm{~min}$ ) and the average estimated blood loss was $728 \mathrm{ml}(\mathrm{SD} \pm 379 \mathrm{ml})$. A postnatal pelvic ultrasound at three months showed no evidence of a niche in any case and an average residual scar thickness of 8.4 $\mathrm{mm}(\mathrm{SD} \pm 1.3 \mathrm{~mm}$; range $5.6-11.0 \mathrm{~mm}$ ).

\section{Discussion}

Although myometrial defect repair has been used for gynaecological indications and has been suggested prepregnancy to improve outcomes, our technique provides an opportunity to repair the defect at the time of repeat LSCS. This has potential benefits, both for future pregnancy with respect to scar rupture and possibly prevention of PAS development. It may also help in reducing the likelihood of scar pregnancy and gynaecological symptoms which are increasingly being attributed to the presence of a scar defect. 


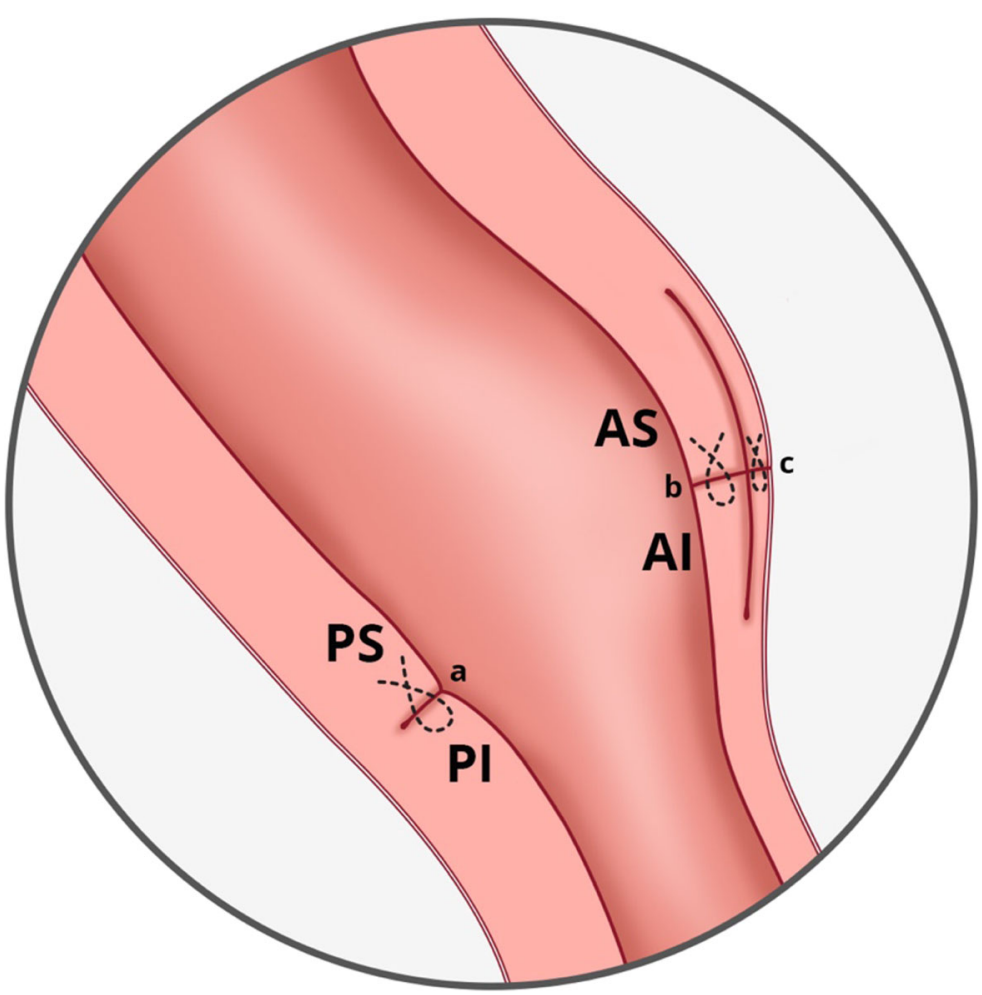

\section{AS- Anterior superior \\ Al - Anterior inferior \\ PS- Posterior superior \\ $\mathrm{PI}$ - Posterior inferior}

Fig. 5 The appearance of anterior and posterior wall defect after repair. AS- Anterior superior. Al - Anterior inferior. PS- Posterior superior. $\mathrm{PI}$ - Posterior inferior. a continuous suture for posterior myometrial defect. $\mathbf{b}$ continuous suture for inner layer of anterior myometrial defect. c continuous suture for outer layer of anterior myometrial defect

It is important to raise awareness that a 'thin lower segment' in repeat CS is actually a myometrial defect with overlying fascia, which should be reconstructed by identifying and approximating the retracted muscle edges at the time of CS, regardless of indication. Differentiating this uterine window with placenta just below the serosa, from a placenta percreta, on antenatal scan and intraoperatively is also key to avoiding unnecessary complex surgical procedures [11].

The underlying principle must be understood and incorporated into obstetric surgical training. Because it is performed within the uterine serosa the technique has a low risk of visceral injury. It can also be used in conjunction with other haemostatic measures such as Bakri balloon, internal iliac occlusion or application of a paracervical tourniquet to reduce blood loss. It includes preservation of the overlying fascia as well as attention to and repair of the posterior uterine muscle, if torn, to avoid this becoming an area of weakness in future pregnancies.

\section{Conclusion}

This technique aimed at repairing the scar defect at the time of repeat Caesarean section resulted in a residual anterior myometrial wall thickness previously associated with good delivery outcomes with the potential to reduce future obstetric and gynaecological morbidity. Awareness and recognition of the condition is important but skill in the technique is easily acquired through practice and we advocate it should be incorporated into basic obstetric surgical training.

\section{Abbreviations}

LSCS: Lower segment caesarean section; RMT: Retro myometrial thickness; PAS: Placenta accreta spectrum; VBAC: Vaginal birth after caesarean section; LUS: Lower uterine segment; AS: Anterior superior; Al: Anterior inferior; PS: Posterior superior; PI: Posterior inferior

\section{Acknowledgments}

We thank Prof Palacios Jaraquemada for his input into the technique and the study and Evan Lim for the medical illustration. 


\section{Authors' contributions}

KML \& AW contributed to manuscript preparation. KHT contributed to the design of the paper and supervised the writing of the article. SHMS contributed to developing the surgical approach and technique. All authors have read and approved the manuscript.

\section{Funding}

The study is supported by Singapore Duke-NUS Benjamin Henry Sheares Professorship in Obstetrics \& Gynecology and Integrated Platform for Research in Advancing Metabolic Health Outcomes of Women \& Children (IPRAMHO) Study Group (NMRC CGAug 16C008). The funding was used to cover the costs of medical illustration and open access submission.

\section{Availability of data and materials}

Data supporting the conclusions of the study is available with Dr. Shahul Hameed Mohamed SIRAJ, Department of Minimally Invasive Surgery, Division of Obstetrics and Gynecology, KK Women's and Children's Hospital, Singapore.

\section{Declarations}

\section{Ethics approval and consent to participate}

The study was granted approval by the Singhealth Centralized Review Board IR Board.

IRB Number (2020-2966 CIRB).

Written consent for the procedure was obtained from all patients.

\section{Consent for publication}

The article does not contain identifiable data from any one patient.

\section{Competing interests}

The authors have no potential conflict of interest pertaining to this study and submission.

\section{Author details}

'Department of Minimally Invasive Surgery, Division of Obstetrics and Gynaecology, KK Women's and Children's Hospital, Singapore, Singapore. 2Department of Maternal Fetal Medicine, Division of Obstetrics and Gynaecology, KK Women's and Children's Hospital, 100 Bukit Timah Road, Singapore 229899, Singapore. ${ }^{3}$ Perinatal Audit and Epidemiology Unit, Division of Obstetrics and Gynaecology, KK Women's and Children's Hospital, Singapore, Singapore.

Received: 14 January 2021 Accepted: 9 August 2021

Published online: 17 August 2021

\section{References}

1. Kok N, Wiersma IC, Opmeer BC, de Graaf IM, Mol BW, Pajkrt E. Sonographic measurement of lower uterine segment thickness to predict uterine rupture during a trial of labor in women with previous cesarean section: a metaanalysis. Ultrasound Obstet Gynecol. 2013;42(2):132-9. https://doi.org/10.1 002/uog. 12479.

2. Einerson BD, Comstock J, Silver RM, Branch DW, Woodward PJ, Kennedy A. Placenta Accreta Spectrum disorder: uterine dehiscence. Not Placental Invasion Obstet Gynecol. 2020;135(5):1104-11. https://doi.org/10.1097/AOG. 0000000000003793.

3. Glenn TL, Bembry J, Findley AD, Yaklic JL, Bhagavath B, Gagneux P, et al. Cesarean scar ectopic pregnancy: current management strategies. Obstet Gynecol Surv. 2018;73(5):293-302. https://doi.org/10.1097/OGX. 0000000000000561.

4. van der Voet LF, Bij de Vaate AM, Veersema S, Brolmann HA, Huirne JA. Long-term complications of caesarean section. The niche in the scar: a prospective cohort study on niche prevalence and its relation to abnormal uterine bleeding. BJOG. 2014;121(2):236-44. https://doi.org/10.1111/14710528.12542

5. Bij de Vaate AJ, Brolmann HA, van der Voet LF, van der Slikke JW, Veersema S, Huirne JA. Ultrasound evaluation of the cesarean scar: relation between a niche and postmenstrual spotting. Ultrasound Obstet Gynecol. 2011;37(1): 93-9. https://doi.org/10.1002/uog.8864.
6. Vervoort AJ, Uittenbogaard LB, Hehenkamp WJ, Brolmann HA, Mol BW, Huirne JA. Why do niches develop in caesarean uterine scars? Hypotheses on the aetiology of niche development. Hum Reprod. 2015;30(12):2695-702. https://doi.org/10.1093/humrep/dev240.

7. Futyma K, Gałczyński K, Romanek K, Filipczak A, Rechberger T. When and how should we treat cesarean scar defect - isthmocoele? Ginekol Pol. 2016; 87(9):664-8. https://doi.org/10.5603/GP.2016.0063.

8. Brahmalakshmy BL, Kushtagi P. Variables influencing the integrity of lower uterine segment in post-cesarean pregnancy. Arch Gynecol Obstet. 2015; 291 (4):755-62. https://doi.org/10.1007/s00404-014-3455-6.

9. Schwickert A, Henrich W. Braun T. Uterine scar thickness as an important outcome for the evaluation of up-to-date uterine closure techniques. Am J Obstet Gynecol. 2018;219(6):632. https://doi.org/10.1016/j.ajog.2018.08.024.

10. Jastrow N, Chaillet N, Roberge S, Morency AM, Lacasse Y, Bujold E. Sonographic lower uterine segment thickness and risk of uterine scar defect: a systematic review. J Obstet Gynaecol Can. 2010;32(4):321-7. https://doi.org/10.1016/S1701-2163(16)34475-9.

11. Jauniaux E, Ayres-de-Campos D, Langhoff-Roos J, Fox KA, Collins S. FIGO classification for the clinical diagnosis of placenta accreta spectrum disorders. Int J Gynaecol Obstet. 2019;146(1):20-4. https://doi.org/10.1002/ ijgo.12761.

\section{Publisher's Note}

Springer Nature remains neutral with regard to jurisdictional claims in published maps and institutional affiliations.
Ready to submit your research? Choose BMC and benefit from:

- fast, convenient online submission

- thorough peer review by experienced researchers in your field

- rapid publication on acceptance

- support for research data, including large and complex data types

- gold Open Access which fosters wider collaboration and increased citations

- maximum visibility for your research: over $100 \mathrm{M}$ website views per year

At $\mathrm{BMC}$, research is always in progress.

Learn more biomedcentral.com/submission 